\title{
Lab view Based Human Power Generator \& Fitness Analyzer
}

\author{
${ }^{1}$ Karthik N, ${ }^{2}$ Kavin T, ${ }^{3}$ porkumaran $\mathrm{K},{ }^{4}$ vinoth kumar N \\ ${ }^{1,2}$ student members, ${ }^{3,4}$ staff members, Department of EEE \\ ${ }^{1,2}$ Dr.N.G.P Institute of Technology, Coimbatore, India.
}

\begin{abstract}
As people over the world continue to search for renewable energy sources, innovative and interesting ideas for generating power are constantly being devised. Those interested in keeping fit and doing exercise in a day to day life, they are using various equipments to burn their calories. Now-a-days spin bike was commonly used in gym as well as home for fitness purpose. In that 4-5 kcal/min of human calories is wasted without any usage. To know the fitness level of human can be find out through laboratory based Vo2 Max test. This is much costly and needs more complex equipments

The objective of the project is to generate the power from the spin bike and to find out the fitness level of human by conducting VO2 max Level test. In this project, the ergo meter cycle is coupled with the PMDC generator which will produce the electrical power when we pedal the cycle. Due to the rotational movement of wheel the generator start rotating and cut the magnetic flux, an EMF get induced. The voltage produced by the bike can be stored in a battery. The heartbeat of the person can be obtained from the heart beat sensor which is used to find the v2 max level of the person. Here the Lab VIEW is used for monitor and control the various parameters of bike such as Calories burned, VO2 max level, heart rate, MET, BMI, Power, battery Status, Speed, Workout Time and Distance.
\end{abstract}

\section{Introduction:}

India suffered peak power shortage of close to 13,000 million units every month, as the thermal power plants struggled to maintain fuel stocks at a reasonable level. And also the hydro plants fails to work in summer session, The Power Ministry expects to generate around 9,20,000 MUs of electricity this fiscal. Out of the total 7, 60,000 MUs would be from coal-based plants. The government might also import 5,000 MUs of electricity from Bhutan.

In India $28.1 \%$ of people suffered in obesity problem according to the National Family Health Survey the peoples approach the gym to reduce their weight. There are several no of gyms running in India. Like ergo meter cycle, spin bike and tread mill can be used by the peoples in gym as well as in home.

From one gym cycle equipment we may get 200 watts/hour and this can be help full to reduce the power problem. By using ergo meter cycle we conduct full fitness check up within 10 minutes with the use of polarized heart rate monitor, it does not require any external equipments to do it. Finally its gives the VO2 max level, heart rate and BMI and other parameters.

\section{Aim:}

To generate the power from human energy and conduct the fitness test by using spin bike cycle and analysis test results by comparing it with the standard results

1. OBJECTIVES:

$>\quad$ To generate the power from human energy

$>\quad$ To reduce power demand by eco-friendly

$>\quad$ To conduct the vo2 max level test

$>\quad$ Day to day fitness monitoring is possible

$>\quad$ To know the current fitness status

\section{Vo2 Max:}

The maximum rate at which an individual consume oxygen during exercise is expressed as VO2 max and it's also called peak aerobic power. It depends on pulmonary, cardiovascular, muscular systems. A measure of cardio-respiratory endurance gives us an indication of the individual's aerobic fitness. Direct measurement of VO2 max requires an extensive laboratory and specialized equipment as well as considerable subject motivation. 


\section{EXISTING METHOD OF VO2 MEASURING}

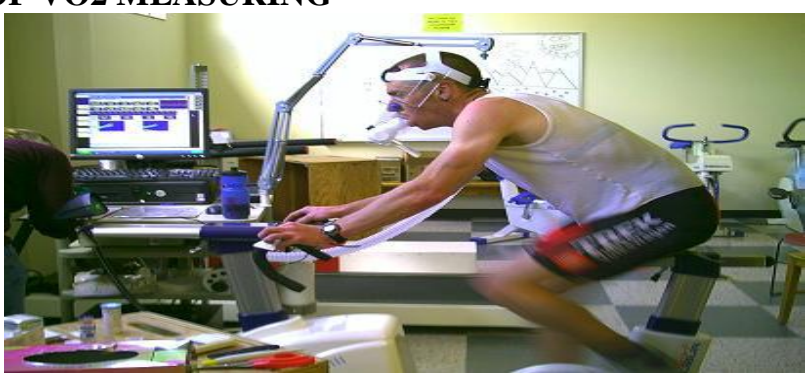

The fig shows the existing method of vo2 measuring.

In proposed method a person monitors the program, after 7 minutes of cycle pedaling for Person Maximum ability with no rest between exercise increments. It's give the accurate result of VO2 max level without any external lab arrangements

\section{Methodolgy:}

While pedaling the cycle, wheel delivers power through its coupling to a PMDC generator. The generator produces a AC output this can be convert into DC using rectifier. That power can be stored in power packs or battery. By this method the energy can be retrieved.

For fitness test the heart rate monitor gives the live heart beat rate during work out, this can be transfer to monitor via Bluetooth. Using the heart rate level other parameters such as VO2 max, fat level, BMI ,MET level etc calculated through the LabVIEW with the use of various formula which is already available.

\section{PROPOSED METHOD}

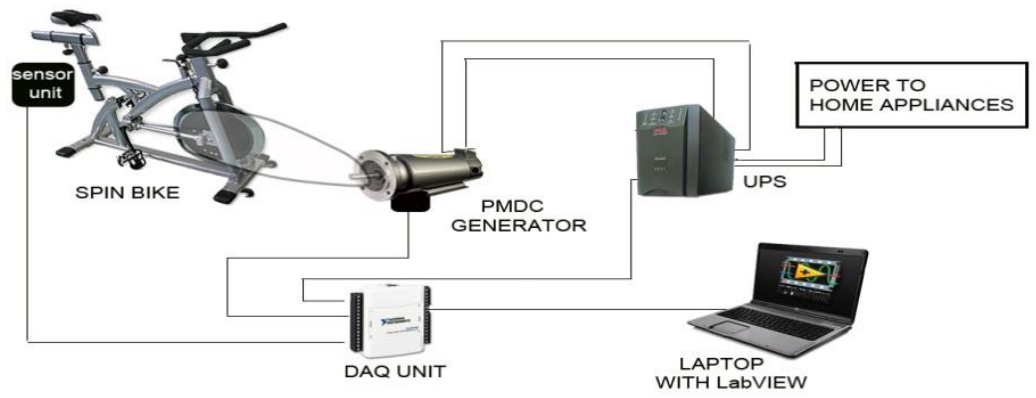

V. RELIABILITY:

Reliability will depend upon how strict the test is conducted and the individual's level of motivation to perform the test. The following link provides a variety of factors that may influence the results and therefore the test reliability

\section{Targeted Peoples:}

It's suitable for sports team and people who are affected in obesity problem

\section{CALORIE CHART:}

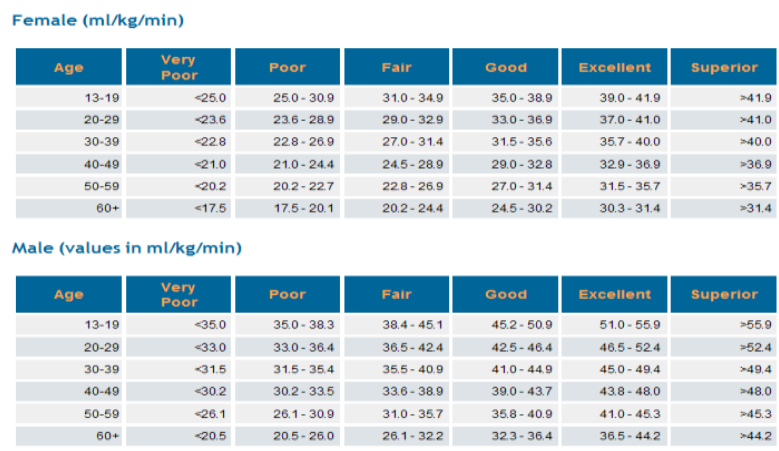

By comparing this chart the final result will be displayed in monitor 


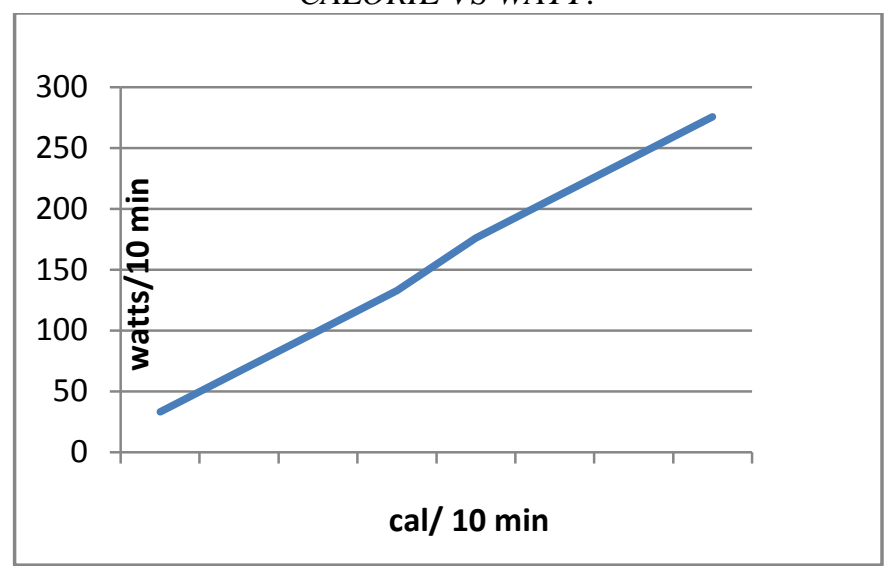

The above relation shows calorie vs power generated in terms of watts. Depends on the motor we've used the power generation level is varying.

VII. FORMULA USED:

$>\quad \mathrm{VO} 2 \max =\mathrm{SM} 2+[\mathrm{b} \times(\mathrm{HR} \max -\mathrm{HR} 2)]$

$>\quad$ Aerobic Fitness Score $=10 \times$ Estimated VO2max

$>\quad \mathrm{SM} 1=\mathrm{VO} 2$ at Second-Last Workload

$>\quad \mathrm{SM} 2=\mathrm{VO} 2$ at Last Workload

The power conversion formulas calorie per minute to watt (cal/min to $\mathrm{w}$ ): $\mathrm{w}=0.6976666667 \times \mathrm{cal} / \mathrm{min}$

VIII. BLOCK DIAGRAM:

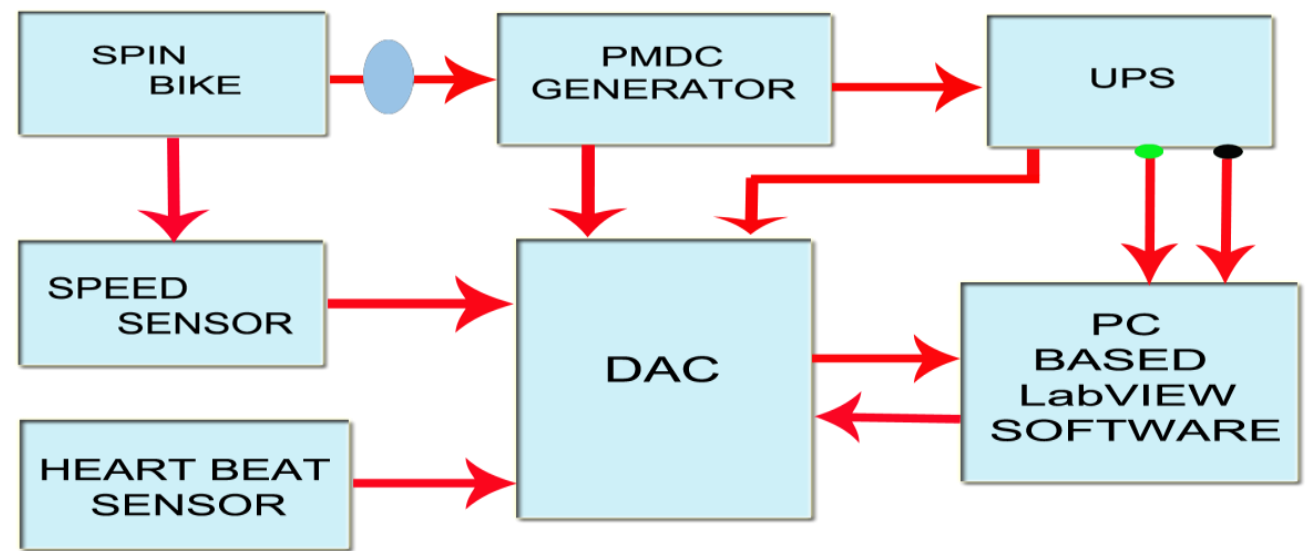

\section{REQUIRED RESOURCES:}

\section{Hardware:}

$>\quad$ Spin bike

$>\quad$ Heart rate sensor

$>\quad$ PMDC generator

$>\quad$ Battery

$>\quad$ Inverter

$>\quad$ MYDAC

Software:

$>\quad$ LabVIEW 2011

2. ADVANTAGES:

$>\quad$ Spin bike is portable and less expensive

Upper body movement is minimal easier to measure exercise heart rate and blood pressure 
$>\quad$ More applicable for measuring cycling performance

Easy generation of power

3. LIMITATIONS:

$>\quad$ Equipment must be well maintained \& calibrated

Running tests are more applicable for measuring running performance.

\section{Application:}

If we pedal for two hours we can produce around 400 watt-hours of power.

That's enough to power

A 200 watt television for two hours.

A 100 watt light bulb for four hours.

A 20 watt laptop PC could be charged for 20 hours.

A 15 watt fluorescent bulb for almost 27 hours.

Fitness test is possible in at home with less time and also day to day fitness monitoring is applicable.

\section{Conclusion:}

This method gives the simple way of produce the power from human energy and conducting the fitness with less cost and time. This will be more beneficial to the society

\section{Refrences:}

http://en.wikipedia.org/wiki/VO2_max

http://stevejenkins.com/blog/2012/05/knowing-myself-part-deux-and-updated-vo2-max-data-from-cycling-test/

http://pedalpowergenerator.com/how-to-build-a-bicyle-generator-free-power.html.

http://www.brianmac.co.uk/astrand.html.

http://www.topendsports.com/testing/tests/astrand.htm

ASTRAND,P.O.\& RHYMING,I.(1954) a monogram for calculate the aerobic capacity

[6] ASTRAND,P.O.\& RHYMING,I.(1954) a monogram
[7] MACKENZIE .B.(2007) Astrand 6 minute cycle test 